\title{
Evaluation of Burn Wound Infection in a Referral Center in Colombia
}

\author{
Sandra L. Jaimes ${ }^{1} \quad$ Carlos E. Ramírez ${ }^{1}$ Andres F. Viviescas ${ }^{2}$ Andres F. Abril ${ }^{2}$ David F. Flórez ${ }^{2}$ \\ Cristian D. Sosa ${ }^{2}$
}

${ }^{1}$ Division of Plastic and Reconstructive Surgery, Burn Center, University Hospital of Santander, Universidad Industrial de Santander; Bucaramanga, Colombia

2 University Hospital of Santander, Universidad Industrial de Santander; Bucaramanga, Colombia

Indian J Plast Surg 2022;55:75-80.
Address for correspondence Sandra Liliana Jaimes, MD, Division of Plastic and Reconstructive Surgery, University Hospital of Santander, Carrera 33 \# 28-126, Bucaramanga, Colombia

(e-mail: salejaos_1906@hotmail.com).

\begin{abstract}
Keywords

- Burn Wound

- Burn Wound Infection

- Burn Wound Sepsis

- Quantitative Biopsy Culture

Introduction Burn wound infection (BWI) is the second most important cause of death in burn patients. There is currently limited data about the incidence and clinical presentation of BWI using quantitative techniques as quantitative biopsy culture (QBC) to prevent progress to burn wound sepsis (BWS).

Methods This is a prospective cohort study of patients diagnosed with BWI, confirmed by QBC, from February 2018 to July 2019 at University Hospital of Santander (HUS). The primary outcome was to determine clinical, microbiological, and histopathological characteristics of patients diagnosed with BWI along with a positive QBC and their relationship with early diagnosis and progression to BWS.

Results 525 patients were admitted to HUS Burn Center. Of those, 44/525 (8.23\%) presented a clinical diagnosis of BWI (median age, 20.5 years [1-67 years]; 25/44 [56.8\%] male). QBC was positive in 26/44 (59\%), Staphylococcus aureus 14/44 (31.8\%), and Pseudomonas aeruginosa $7 / 44$ (15.9\%) were the mainly etiological agents isolated. Bacterial resistance to antibiotics was mostly to beta-lactams in 14/44 (31.8\%), corresponding to methicillin-resistant Staphylococcus aureus (MRSA). Clinical signs more related to infection were erythema in $33 / 44$ (61.3\%). As many as $10 / 44$ (22.7\%) progressed to sepsis and 2/44 (6\%) died.

Conclusion BWI increases hospitalization time and number of surgeries, increasing the risk of sepsis and death. The QBC allows an accurate diagnosis with lesser falsepositive cases that impact antibiotic resistance and mortality. Protocols targeting this problem are needed to decrease the impact of this.
\end{abstract}

\section{Introduction}

Burn wound infection (BWI) is a significant cause of morbidity and mortality in burn patients. The implementation of an early and aggressive debridement and silver sulfadiazine in the 90s pushed BWI from being the main cause of death to the second position, preceded only by pneumonia. ${ }^{1,2}$ However, this complication is associated with high mortality, received

September 2, 2020 accepted after revision March 17, 2021

published online

February 9, 2022
DOI https://doi.org/ 10.1055/s-0041-1740494. ISSN 0970-0358.

\footnotetext{
(c) 2022. Association of Plastic Surgeons of India. All rights reserved. This is an open access article published by Thieme under the terms of the Creative Commons Attribution-NonDerivative-NonCommercial-License, permitting copying and reproduction so long as the original work is given appropriate credit. Contents may not be used for commercial purposes, or adapted, remixed, transformed or built upon. (https://creativecommons.org/ licenses/by-nc-nd/4.0/)

Thieme Medical and Scientific Publishers Pvt. Ltd., A-12, 2nd Floor, Sector 2, Noida-201301 UP, India
} 
especially in major burn patients (adults $>20 \%$ total body surface area [TBSA]; children $>10 \%$ TBSA), due to a rapid progression following immunosuppression induced by burn injuries. $^{2,3}$

BWI is usually caused by nosocomial microorganisms with high virulence in patients with major burns who are treated in a critical care facility. Initially, burn wound (BW) surface is sterile but rapidly colonized by bacteria of skin flora, creating a dynamic exchange with the external environment, denominated biofilms. ${ }^{4}$ The objective of surgical debridement is to remove biofilms and control their multiplication using topical derivatives of sulfadiazine. ${ }^{5}$ Thus, BW must be assessed during each wound dressing change by a trained surgeon to differentiate clinical signs of normal BW from signs of burn wound infection (BWI). ${ }^{5}$

Many clinical variables such as comorbidities, clinical presentation, and microbiological virulence have been associated with the progression of burn wound sepsis (BWS). ${ }^{6}$ For BWI assessment, qualitative techniques such as burn surface swab and culture by standard agar are used, but these have a higher rate of false positives, and overdiagnosis is common. There is not enough evidence to recommend one over the other, owing to the few studies in BWI confirmed by quantitative biopsy culture (QBC). ${ }^{6,7}$

This study describes clinical characteristics, microbiological and histopathological outcomes, and sociodemographic variables of patients diagnosed with BWI in our burn unit, and BWS and their relationship with QBC positive and progression to BWS and death. The Burn Intensive Care Unit of University Hospital of Santander (HUS) in Bucaramanga, Colombia, includes a population of five million people, and over 300 patients with burns are admitted every year

\section{Materials and Methods}

This study included all the patients admitted from February 2018 to July 2019 to the HUS's Burn Intensive Care Unit and who were diagnosed with BWI and BWS, according to the American's Burn Association (ABA) criteria. ${ }^{8}$ In all cases, the diagnosis was confirmed by QBC; two samples were taken in all cases, and mediums used for sample transfer were saline solution $0.9 \%$ for culture that was processed in blood agar and formaldehyde for histopathologic study. ${ }^{1}$ The patients were monitored from clinical diagnosis until their discharge or mortality. Medical records and laboratory and pathology results were reviewed. Patients with a diagnosis of BWI prior to admission, those who had received antibiotic treatment before $\mathrm{QBC}$ test, and those with no clinical history data and/or incomplete histopathological and laboratory studies were excluded. All patients were taken to surgical debridement before admission to the burn unit. Data were tabulated with the help of Microsoft Excel and processed in 14th STATA version program. A univariate analysis was performed based on medians, means, proportions, and ranges. A bivariate analysis was used to find possible variables associated with outcomes, using Chi-square (or Fischer) and MannWhitney test.

\section{Results}

A total of 525 burned patients were admitted to the HUS Burn Unit from February 1, 2018, to July 31, 2019; out of these $44 / 525$ (8.3\%) developed BWI, based on clinical diagnosis, and $10 / 44$ (22.7\%) progressed to BWS.

Table 1 Sociodemographic and clinical characteristics

\begin{tabular}{|c|c|c|c|}
\hline $\begin{array}{l}\text { Sociodemographic and } \\
\text { clinical characteristics }\end{array}$ & $n$ & $\%$ & Cl 95\% \\
\hline \multicolumn{4}{|l|}{ Sex } \\
\hline Female & 19 & 43.2 & $27.9-58.4$ \\
\hline Male & 25 & 56.8 & $41.6-72.1$ \\
\hline \multicolumn{4}{|l|}{ Age } \\
\hline Pediatric (under 18 years) & 17 & 38.6 & $23.7-53.6$ \\
\hline Adult (above18 years) & 27 & 61.4 & $46.4-76.3$ \\
\hline \multicolumn{4}{|l|}{ Comorbidities } \\
\hline No & 30 & 68.2 & $53.9-82.5$ \\
\hline Yes & 14 & 31.8 & $17.5-46.1$ \\
\hline \multicolumn{4}{|l|}{ Mechanism } \\
\hline Scalds & 24 & 54.6 & $39.2-69.9$ \\
\hline Direct contact & 18 & 40.9 & $25.8-56.0$ \\
\hline Electric & 2 & 4.5 & $0.0-10.9$ \\
\hline \multicolumn{4}{|l|}{ Depth } \\
\hline Second degree & 32 & 72.7 & $59.0-86.4$ \\
\hline Third degree & 12 & 27.3 & $13.6-41.0$ \\
\hline \multicolumn{4}{|l|}{ Extension } \\
\hline $\begin{array}{l}\text { Minor (less than } 20 \% \text { TBSA } \\
\text { adults or } 10 \% \text { in children) }\end{array}$ & 25 & 56.8 & $41.6-72.1$ \\
\hline $\begin{array}{l}\text { Major (above those } \\
\text { percentages) }\end{array}$ & 19 & 43.2 & $27.9-58.4$ \\
\hline \multicolumn{4}{|l|}{ Location $^{\text {a }}$} \\
\hline Upper limb & 32 & 72.7 & $59.0-86.4$ \\
\hline Lower limb & 28 & 63.6 & $48.8-78.4$ \\
\hline Head and neck & 27 & 61.4 & $46.4-76.3$ \\
\hline Anterior torso & 18 & 40.9 & $25.8-56.0$ \\
\hline Posterior torso & 12 & 27.3 & $13.6-41.0$ \\
\hline \multicolumn{4}{|l|}{ Signs of infection ${ }^{\text {a }}$} \\
\hline Erythema & 33 & 75.0 & $61.7-88.3$ \\
\hline Edema & 27 & 61.4 & $46.4-76.3$ \\
\hline Exudate & 20 & 45.5 & $30.1-60.8$ \\
\hline Eschar discoloration & 15 & 34.1 & $19.5-48.7$ \\
\hline Pain increasing & 9 & 20.5 & $8.0-32.9$ \\
\hline Separation of eschar & 7 & 15.9 & $4.7-27.2$ \\
\hline Loss of skin grafts & 1 & 2.3 & $0.0-6.9$ \\
\hline Lymphangitis & 1 & 2.3 & $0.0-6.9$ \\
\hline
\end{tabular}

Abbreviations: $\mathrm{Cl}$, confidence interval; TBSA, total body surface area. HUS Bucaramanga 2017-2018.

${ }^{\mathrm{a}}$ Chi-Square Test (or Fisher's Test) 
The average age was 27 years, with a median of 20.5 years (range, 1-67 years), with a predominant adult population and male sex. Some comorbidities that caused immune disorders (diabetes, HIV, chronic cortical dependent disease, malnutrition) were recorded (-Table 1).

Scalds were the most frequent cause, followed by contact burns; second-degree burns predominated. The majority had less than $20 \%$ TBSA burns in adults and less than $10 \%$ TBSA burns in children. However, 19/44 (43.2\%) had major burns. Of these, 10/44 (30.2\%) were adults and 9/44 (13\%) children. Most of them presented with more than one burned anatomical area, and the most frequent regions involved were the upper limbs, followed by the lower limbs. All patients with BWS had major burns (-Table 1 ).

Among the signs of infection, erythema was predominant (redness greater than $1 \mathrm{~cm}$ from the burn wound border), followed by edema, and exudate and eschar discoloration. In patients with BWS, erythema and edema were found in the same frequency $7 / 10$ (70\%) for each one (-Table 1). With regard to clinical presentation, latency period was defined as the time between burn wound and first signs of infection; early if clinical signs were evidenced into the first 72 hours since admission in Burn Unit and late if occurred after this time. Most cases developed signs in the first 72 hours after

Table 2 Clinical evolution

\begin{tabular}{|l|l|l|l|}
\hline Clinical evolution & $\boldsymbol{n}$ & $\%$ & $\mathrm{Cl} 95 \%$ \\
\hline Latency period & & & \\
\hline Early-onset (before 72 hours) & 41 & 93.2 & $85.4-100.0$ \\
\hline Late-onset (after 72 hours) & 3 & 6.8 & $0.0-14.6$ \\
\hline Infection & & & \\
\hline No & 17 & 38.6 & $23.7-53.6$ \\
\hline Yes & 27 & 61.4 & $46.4-76.3$ \\
\hline Initial treatment & & & \\
\hline No & 3 & 6.8 & $0.0-14.6$ \\
\hline Yes & 38 & 86.4 & $75.8-96.9$ \\
\hline Not reported & 3 & 6.8 & $0.0-14.6$ \\
\hline Debridement & & & \\
\hline No & 6 & 13.6 & $3.1-24.2$ \\
\hline Yes & 38 & 86.4 & $75.8-96.9$ \\
\hline Skin graft & & & \\
\hline No & 13 & 29.6 & $15.5-43.6$ \\
\hline Yes & 31 & 70.4 & $56.4-84.5$ \\
\hline Health care-associated infection & & & \\
\hline No & 32 & 72.7 & $59.0-86.4$ \\
\hline Yes & 12 & 27.3 & $13.6-41.0$ \\
\hline Mortality & 2 & & \\
\hline No & 41 & 95.4 & $88.8-100.0$ \\
\hline Yes & & & $0.0-11.2$ \\
\hline
\end{tabular}

Abbreviations: $\mathrm{Cl}$, confidence interval; $n$, number. HUS Bucaramanga 2017-2018

${ }^{a}$ Chi-Square Test (or Fisher's Test) arrival at Burn Unit (41; 93.2\%), corresponding to early infection (-Table 2).

QBC was positive in 27/44 patients (61.4\%); all of them presented quantitative culture with more than $10^{3}$ colonyforming units (CFUs) per gram of tissue. However, in histopathological reports, the microbial invasion was not differentiated between IIB and IIC grades, according to Mitchell et al classification. ${ }^{9}$ There was a slight predominance of superficial invasion above the deep one (-Table $\mathbf{3}$ ).

Table 3 Histopathological findings

\begin{tabular}{|c|c|c|c|}
\hline Histopathological findings & $n$ & $\%$ & Cl $95 \%$ \\
\hline \multicolumn{4}{|l|}{ Invasion } \\
\hline Superficial & 6 & 13.6 & $3.1-24.2$ \\
\hline Deep & 5 & 11.4 & $1.6-21.1$ \\
\hline Not determined & 33 & 75.0 & $61.7-88.3$ \\
\hline \multicolumn{4}{|l|}{ Infiltration } \\
\hline I & 2 & 4.6 & $0.0-10.9$ \\
\hline $\mathrm{IA}$ & 0 & 0.0 & - \\
\hline I B & 2 & 4.6 & $0.0-10.9$ \\
\hline II & 6 & 13.6 & $3.1-24.2$ \\
\hline II A & 5 & 11.4 & $1.6-21.1$ \\
\hline II B & 7 & 15.9 & $4.7-27.2$ \\
\hline$\| C$ & 9 & 20.5 & $8.0-32.9$ \\
\hline Not observed & 13 & 29.6 & $15.5-43.6$ \\
\hline \multicolumn{4}{|l|}{ Etiological agents* } \\
\hline S. aureus & 14 & 31.8 & $17.5-46.1$ \\
\hline P. aeruginosa & 7 & 15.9 & $4.7-27.2$ \\
\hline K. pneumoniae & 3 & 6.8 & $0.0-14.6$ \\
\hline S. marcescens & 2 & 4.6 & $0.0-10.9$ \\
\hline A. baumanii & 2 & 4.6 & $0.0-10.9$ \\
\hline S. saprophyticus & 1 & 2.3 & $0.0-6.9$ \\
\hline A. veronni & 1 & 2.3 & $0.0-6.9$ \\
\hline P. mirabilis & 1 & 2.3 & $0.0-6.9$ \\
\hline P. penneri & 1 & 2.3 & $0.0-6.9$ \\
\hline E. faecalis & 1 & 2.3 & $0.0-6.9$ \\
\hline E. aerogenes & 1 & 2.3 & $0.0-6.9$ \\
\hline Fungi & 1 & 2.3 & $0.0-6.9$ \\
\hline Other & 1 & 2.3 & $0.0-6.9$ \\
\hline \multicolumn{4}{|l|}{ Bacterial resistance } \\
\hline Beta-lactams & 14 & 31.8 & $17.5-46.1$ \\
\hline Carbapenems & 2 & 4.6 & $0.0-10.9$ \\
\hline Aminoglycosides & 1 & 2.3 & $0.0-6.9$ \\
\hline Lincosamides & 2 & 4.6 & $0.0-10.9$ \\
\hline Quinolones & 3 & 6.8 & $0.0-14.6$ \\
\hline Sulfonamides & 7 & 15.9 & $4.7-27.2$ \\
\hline Ureidopenicillins & 1 & 2.3 & $0.0-6.9$ \\
\hline
\end{tabular}

HUS Bucaramanga 2017-2018. 
Table 4 Bivariate analysis of sociodemographic and clinical characteristics and signs of infection

\begin{tabular}{|c|c|c|c|c|c|c|}
\hline Sociodemographic and clinical variables & $n$ & No infection & Infection & OR & $\mathrm{Cl}$ & $p$-value ${ }^{\mathrm{a}}$ \\
\hline \multicolumn{7}{|l|}{ Sex } \\
\hline Female & 19 & 42.1 & 57.9 & & & \\
\hline Male & 25 & 36.0 & 64.0 & 1.29 & $0.31-5.18$ & 0.680 \\
\hline \multicolumn{7}{|l|}{ Age } \\
\hline Pediatric & 17 & 41.2 & 58.8 & & & \\
\hline Adult & 27 & 37.0 & 63.0 & 1.19 & $0.28-4.85$ & 0.784 \\
\hline \multicolumn{7}{|l|}{ Comorbidities } \\
\hline No & 30 & 36.7 & 63.3 & & & \\
\hline Yes & 14 & 42.9 & 57.1 & 0.77 & $0.17-3.49$ & 0.694 \\
\hline \multicolumn{7}{|l|}{ Mechanism } \\
\hline Scalds & 24 & 37.5 & 62.5 & & & \\
\hline Direct contact & 18 & 44.4 & 55.6 & & & \\
\hline Electrical & 2 & 0.0 & 100.0 & 0.9 & $0.22-3.61$ & 0.865 \\
\hline \multicolumn{7}{|l|}{ Depth } \\
\hline Second degree & 32 & 46.9 & 53.1 & & & \\
\hline Third degree & 12 & 16.7 & 83.3 & 4.41 & $0.73-46.3$ & 0.066 \\
\hline \multicolumn{7}{|l|}{ Extension } \\
\hline Minor & 25 & 44.0 & 56.0 & & & \\
\hline Major & 19 & 31.6 & 68.4 & 1.70 & $0.41-7.28$ & 0.402 \\
\hline \multicolumn{7}{|l|}{ Location $^{a}$} \\
\hline A single affected anatomical area & 15 & 40.0 & 60.0 & & & \\
\hline More than one affected anatomical area & 29 & 37.9 & 62.1 & 1.09 & $0.24-4.62$ & 0.894 \\
\hline \multicolumn{7}{|l|}{ Signs of infection ${ }^{a}$} \\
\hline Erythema & 33 & 33.3 & 66.7 & 2.4 & $0.47-12.2$ & 0.210 \\
\hline Edema & 27 & 33.3 & 66.7 & 1.77 & $0.42-7.32$ & 0.363 \\
\hline Exudate & 20 & 35.0 & 65.0 & 1.32 & $0.33-5.43$ & 0.651 \\
\hline Eschar discoloration & 15 & 40.0 & 60.0 & 0.91 & $0.21-4.06$ & 0.894 \\
\hline Pain increasing & 9 & 44.4 & 55.6 & 0.73 & $0.13-4.46$ & 0.688 \\
\hline Separation of eschar & 7 & 40.0 & 60.0 & 4.57 & $0.46-223,1$ & 0.894 \\
\hline Loss of skin grafts & 1 & 100.0 & 0.0 & - & - & - \\
\hline Lymphangitis & 1 & 100.0 & 0.0 & - & - & - \\
\hline
\end{tabular}

Abbreviations: $\mathrm{Cl}$, confidence interval; OR, odds ratio.

HUS Bucaramanga 2017-2018.

${ }^{\mathrm{a}}$ Test chi cuadrado (o Fisher).

The most etiological agents were Staphylococcus aureus and Pseudomonas aeruginosa. Others presented with more than one bacteria growth. The bacterial resistance to antibiotics was mostly to beta-lactams, corresponding to methicillin-resistant S. aureus (MRSA) in all these cases. The same etiological agents were found in patients who developed BWS, with five cases each (-Table 3 ).

\section{Statistical Analysis}

The bivariate analysis to identify clinical variables associated with a positive histopathological result evidenced that the compromise of more than one anatomical segment has the higher relationship, followed by adult age and comorbidities.
However, none of these were statistically significant (-Table 4).

On clinical variables, rapid eschar separation was the most common sign in the cases of positive, followed by eschar discoloration, disproportionate pain, and exudate (-Table 4). The median of hospitalization days was 34 days (range, 7-146 days), and an average of 3.2 surgical procedures were performed per patient.

\section{Discussion}

BWI remains a leading cause of morbidity and mortality, despite advances in the use of topical and parenteral 
antimicrobial therapy and the practice of early tangential excision. ${ }^{10,11}$ BWI is a clinical diagnosis, based on the evaluation of burn wound surface. In noninfected BW, overdiagnosis results in unnecessary antibiotic therapy, which has seen increased antibiotic resistance in the last decade. ${ }^{12-15}$ Discoloration and separation of the eschar are the signs with the highest correlation with positive QBC and BWI, in others studies8 skin graft loss has been reported too, although these were not evident in these cohort of patients.

For confirmation of BWI, many centers globally, including the UK, use qualitative techniques in contrast to $47 \%$ in the USA that uses QBC, despite correlation between a negative culture and negative histopathologic biopsy having a specificity of $96 \%$ to discard $\mathrm{BWI}^{9}$; the reason is that there are few studies using QBC according to Mitchell et al. Techniques (taking two samples with at least 0.5 grams of tissue) that evaluated their impact in early detection of BWI diagnosis were early specific antibiotic treatment, lower nosocomial infections, lesser surgical procedures and lesser time of hospitalization, as reported by Halstead et al. ${ }^{7}$ in their systematic review; however the evidence based on the utility and reliability of quantitative microbiology for diagnosing or predicting clinical outcomes in burned patients is limited and poorly reported. ${ }^{7-16}$

Our results confirm the results of previous studies in burn intensive care units (Lilly et $\mathrm{al}^{17}$, Clark et $\mathrm{al}^{18}$ ) where antibiotic resistance to beta-lactams is the most frequent, followed by sulphonamide resistance. Also describing infection by multidrug resistant microorganism was associated with an increased progression to sepsis an death. ${ }^{14,17-20}$

Probably, the major utility of $\mathrm{QBC}$ is in the diagnosis of BWI in microbial barrier property (MBP), where signs of infection are inconsistent, due to immunosuppression induced by the burn. ${ }^{6,9}$ Once white blood cells (WBCs) are colonized, qualitative techniques has a higher rate of false positives; $43 \%$ of our patients corresponded to MBP, of these $23 \%$ progressed to BWS with positive $\mathrm{QBC}$ in all cases, and an early and specific antibiotic therapy was started, compared with Ramirez et al study in the same unit burn care, where there was a reduction of $6 \%$ reduction of mortality after implementation of QBC in a longer follow-up time. 1,2,9,16,21

Histopathological changes did not correlate with BWS progression, and the level of invasion did not determine BWS progression; however, in this study, many samples were not were differentiated like Wolfrey et al study. ${ }^{21}$

Prevention of BWI requires an early clinical diagnosis and a specific antibiotic treatment to prevent progression to BWS. QBC allows an accurate diagnosis with lesser falsepositive cases that impact the long-term reduction in antibiotic resistance and mortality. ${ }^{16}$ More studies are necessary for a unified approach.

\section{Conclusion}

BWI is a frequent complication in BW patients, and overdiagnosis is also common, as signs of infection are often confused with signs of burn wound healing. Confirmation of the diagnosis is the main goal, and quantitative techniques are an accurate way to select a specific antibiotic therapy and prevent progression to sepsis.

\section{Declaration}

None.

\section{Financial Disclosure and Products}

None of the authors has a financial interest in any of the products, devices, or drugs mentioned in this manuscript.

\section{Author's Role/Participation in the Authorship of the Manuscript}

All the authors have made substantial contributions to the realization of this manuscript, including study design, collection of data, data analysis/interpretation, and writing of the manuscript.

\section{Conflict of Interest}

None.

\section{Acknowledgment}

We would like to thank the Plastic Surgery Service of the HUS, especially Universidad Industrial de Santander(UIS), places where these ideas were developed. We would also like to thank Dr. Hector Julio Melendez and Dr. Juan Carlos Uribe, Epidemiologists, for their contribution in research protocol and in the analysis of results.

\section{References}

1 Church D, Elsayed S, Reid O, Winston B, Lindsay R. Burn wound infections. Clin Microbiol Rev 2006;19(02):403-434

2 Ramirez-Blanco CE, Ramirez-Rivero CE, Diaz-Martinez LA, SosaAvila LM. Infection in burn patients in a referral center in Colombia. Burns 2017;43(03):642-653

3 Fitzwater J, Purdue GF, Hunt JL, O'Keefe GE. The risk factors and time course of sepsis and organ dysfunction after burn trauma. J Trauma 2003;54(05):959-966

4 Stoodley P, Sauer K, Davies DG, Costerton JW. Biofilms as complex differentiated communities. Annu Rev Microbiol 2002; 56:187-209

5 Altoparlak U, Erol S, Akcay MN, Celebi F, Kadanali A. The timerelated changes of antimicrobial resistance patterns and predominant bacterial profiles of burn wounds and body flora of burned patients. Burns 2004;30(07):660-664

6 Baker CC, Miller CL, Trunkey DD. Predicting fatal sepsis in burn patients. J Trauma 1979;19(09):641-648

7 Halstead FD, Lee KC, Kwei J, Dretzke J, Oppenheim BA, Moiemen NS. A systematic review of quantitative burn wound microbiology in the management of burns patients. Burns 2018;44(01):39-56

8 Greenhalgh DG, Saffle JR, Holmes JH IV, et al; American Burn Association Consensus Conference on Burn Sepsis and Infection Group. American Burn Association consensus conference to define sepsis and infection in burns. J Burn Care Res 2007;28(06): 776-790

9 Mitchell V, Galizia JP, Fournier L. Precise diagnosis of infection in burn wound biopsy specimens. Combination of histologic technique, acridine orange staining, and culture. J Burn Care Rehabil 1989;10(03):195-202

10 Mayhall CG. The epidemiology of burn wound infections: then and now. Clin Infect Dis 2003;37(04):543-550 
11 Goswami P, Sahu S, Singodia P, et al. Early excision and grafting in burns: an experience in a tertiary care industrial hospital of eastern India. Indian J Plast Surg 2019;52(03):337-342

12 Vickers ML, Dulhunty JM, Ballard E, et al. Risk factors for multidrug-resistant Gram-negative infection in burn patients. ANZ J Surg 2018;88(05):480-485

13 Wang Z, Qin RR, Huang L, Sun LY. Risk factors for carbapenemresistant Klebsiella pneumoniae infection and mortality of Klebsiella pneumoniae infection. Chin Med J (Engl) 2018;131(01):56-62

14 Munier AL, Biard L, Legrand M, et al. Incidence, risk factors and outcome of multi-drug resistant Acinetobacter baumannii nosocomial infections during an outbreak in a burn unit. Int J Infect Dis 2019;79:179-184

15 Strassle PD, Williams FN, Weber DJ, et al. Risk factors for healthcare-Associated infections in adult burn patients. Infect Control Hosp Epidemiol 2017;38(12):1441-1448

16 Kwei J, Halstead FD, Dretzke J, Oppenheim BA, Moiemen NS. Protocol for a systematic review of quantitative burn wound microbiology in the management of burns patients. Syst Rev 2015;4(01):150

17 Lilly HA, Lowbury EJ, Wilkins MD, Cason JS. Staphylococcal sepsis in a burns unit. J Hyg (Lond) 1979;83(03):429-435

18 Clark NM, Patterson J, Lynch JP III. Antimicrobial resistance among gram-negative organisms in the intensive care unit. Curr Opin Crit Care 2003;9(05):413-423

19 Haraga I, Nomura S, Fukamachi S, et al. Emergence of vancomycin resistance during therapy against methicillin-resistant Staphylococcus aureus in a burn patient-importance of lowlevel resistance to vancomycin. Int J Infect Dis 2002;6(04): 302-308

20 Hsueh PR, Teng LJ, Yang PC, Chen YC, Ho SW, Luh KT. Persistence of a multidrug-resistant Pseudomonas aeruginosa clone in an intensive care burn unit. J Clin Microbiol 1998;36(05):1347-1351

21 Woolfrey BF, Fox JM, Quall CO. An evaluation of burn wound quantitative microbiology. I. Quantitative eschar cultures. Am J Clin Pathol 1981;75(04):532-537 